\title{
As trajetórias de jovens egressos universitários e sua inserção profissional
}

\section{The trajectories of young university graduates and their professional insertion}

\author{
Naiara Gracia Tibola ${ }^{1 *}$, Tânia Regina Raitz
}

\begin{abstract}
RESUMO
O presente artigo é uma pesquisa realizada com jovens egressos universitários de uma insituição de nível superior situada no Estado de Santa Catarina na região do Alto Vale do Itajaí, no que se refere a suas trajetórias laborais e inserção profissional. O objetivo foi analisar a trajetória formativa e laborar de jovens egressos universitários no que diz respeito a sua inserção profissional. Como base teórica autores como Rocha-de-Oliveira e Piccinini (2012), Groppo (2015), Dubar (2012), Melucci (2005), entre outros deram o suporte teórico necessário para fundamentação e análise dos dados. A abordagem da pesquisa é qualitativa, e teve por estratégia um questionário com perguntas abertas e fechadas encaminhado através do Google Formulário, que obteve um total de 134 respostas de egressos de dez cursos, sendo eles: Administração, Ciências Contábeis, Ciências Econômicas, Direito, Enfermagem, Educação Física Bacharelado, Educação Física Licenciatura, Engenharia Civil, Psicologia e Sistemas de Informações, concluintes no período de 2014 a 2018. Os resultasos obtidos propõem um reflexão impoprtante sobre o processo de inserção profissional dos jovens egressos e o suporte da universidade durante o período da graduação aos estudantes.
\end{abstract}

Palavras-chave: Inserção Profissional; Jovens egressos; Trajetória profissional.

\begin{abstract}
This article is a research carried out with young university graduates from a higher education institution located in the State of Santa Catarina in the Alto Vale do Itajai region, regarding their work trajectories and professional insertion. The objective was to analyze the formative trajectory and work of young university graduates regarding their professional insertion. As a theoretical basis, authors such as Rocha-de-Oliveira and Piccinini (2012), Groppo (2015), Dubar (2012), Melucci (2005), among others, provided the necessary theoretical support to substantiate and analyze the data. The research approach is qualitative, and had as a strategy a questionnaire with open and closed questions sent through Google Form, which obtained a total of 134 responses from graduates of ten courses, namely: Administration, Accounting, Economics, Law, Nursing, Physical Education Bachelor, Physical Education Licentiate, Civil Engineering, Psychology and Information Systems, graduates in the period 2014 to 2018. The results obtained propose an important reflection on the process of professional insertion of young graduates and the support of the university during the period of graduation to students.
\end{abstract}

Keywords: Professional Insertion; Young graduates; Professional trajectory.

${ }^{1}$ UNIVALI - Universidade do Vale do Itajaí.

*E-mails: tibola@univali.br; raitztania@gmail.com 


\section{INTRODUÇÃO}

As intensas e velozes transformações observadas no mundo do Trabalho, no século XXI, afetam, sobremaneira, as trajetórias de nossos jovens nas mais diversas áreas, especialmente aquelas que se direcionam ao processo de inserção profissional. Desta forma, o ingresso dos jovens no ensino superior em busca de uma formação e qualificação para o mercado de trabalho corresponde também a uma busca por uma melhor inserção profissional. Para Antunes (2018, p. 27), "é preciso compreender a nova morfologia do trabalho a partir de quem é a nova classe trabalhadora hoje", que pode ser um trabalhador com estabilidade (órgãos públicos), contratado assalariado, terceirizado, autônomo, atividades em home-office, o autor, nesse sentido, amplia e diz: "um profissional multifacetado, de características variadas" (ANTUNES, 2003, p.235).

Os jovens têm sido os mais afetados pelo fenômeno, nomeadamente de processos de transição da universidade para o mercado de trabalho, o que se traduz numa forte tendência generalizada para o aumento da taxa de desemprego e da precariedade nas relações de trabalho. A saída tardia da casa dos pais e o alargamento da faixa etária têm se constituído em discussões institucionais, uma vez que as dificuldades, na transição para o mercado de trabalho, revelam-se incertas e não lineares, sendo marcadas pela precariedade e flexibilização do emprego, limitando os projetos de vida dos jovens, particularmente a saída de casa dos pais, o casamento e a constituição de família.

Os estudos relativos à problemática da transição dos jovens, após a formação escolar, evidenciam que este processo tem sofrido alterações profundas, o que nos leva ao questionamento dos fatores que influenciam o processo de transição para o mercado de trabalho (RAITZ, 2011, s/p.). É preciso observar como os jovens que ingressam no ensino superior, na busca por qualificação e melhor alocação no mercado de trabalho, estão após o período de conclusão do curso.

Para compreender melhor a dinâmica, foram selecionados 10 (dez) cursos de graduação em que houve concluintes (egressos), nos períodos de 2014 a 2018, e que estariam inseridos no mercado de trabalho, trilhando uma caminhada no período compreendido para a pesquisa. Os cursos selecionados foram: Administração, Ciências Contábeis, Ciências Econômicas, Direito, Enfermagem, Educação Física Bacharelado, Educação Física Licenciatura, Engenharia Civil, Psicologia e Sistemas de Informações. A instituição oferta diversos cursos, para a pesquisa, selecionaram-se cursos com um 
número maior de procura e que obtiveram concluintes no período citado. Os dados foram coletados por meio de um questionário online (Google Formulários) e analisados através da técnica de análise de conteúdo (BARDIN, 2016).

Com o intuito de compreender melhor esse processo foi realizada uma investigação, cujo problema de pesquisa teve como norte a seguinte questão: Como se deu a trajetória formativa e laboral de jovens egressos universitários no que se refere a sua inserção profissional? O objetivo foi analisar a trajetória formativa e laboral de jovens egressos universitários no que diz respeito a sua inserção profissional.

\section{FUNDAMENTOS SOBRE JUVENTUDES E INSERÇÃO PROFISSIONAL}

É necessário enxergar os jovens com diversos olhares, "tais diferenças entre os jovens se vinculam às experiências de cada geração e aos contextos específicos e globais aos quais pertencem" (MELO, BORGES, 2007, p. 378), as modificações sociais, culturais e questões relacionadas à construção histórica de gênero são fatores que contribuem na tecitura das identidades juvenis. Na elaboração de Políticas Públicas é importante levar em consideração a definição de direitos ou de deveres e de levantamentos demográficos na definição da juventude, no interior de um recorte que se constitui num viés aceitável, no entanto, é preciso ter cuidado para não cair em determinismos e passar a ver a juventude de forma homogênea e linear, numa perspectiva biologizante dessa etapa da vida.

Na perspectiva histórico-sociocultural a juventude é definida com uma categoria específica da sociedade, não é estática, é heterogênea, que apresenta semelhanças na sua coletividade e diferenças cunhadas pelo contexto que está inserida, ou seja, em cada período da história a juventude passa por uma definição se modificando culturalmente e deixando sua marca na sociedade, conforme sinaliza Dayrell (2003) em seu artigo denominado "O jovem como sujeito social": A juventude constitui um momento determinado, mas não se reduz a uma passagem; ela assume uma importância em si mesma. Todo esse processo é influenciado pelo meio social concreto no qual se desenvolve e pela qualidade das trocas que este proporciona (DAYRELL, 2003, p.42).

O conceito de juventude reconhecido pela abordagem histórico-sócio-cultural busca compreendê-la em uma concepção histórica de seu desenvolvimento focando-a em totalidade e em seu contexto. Neste aspecto, Raitz (2003), enfatiza que: 
como sujeitos histórico-sociais, a realidade e as análises não devem se manter estáticas durante o passar dos anos, portanto, estas mudanças são absorvidas de modos diversos, dependendo de cada momento histórico (RAITZ, 2003, p.30).

O momento histórico que estamos transcorrendo mostra as características de diversidade e à heterogeneidade dos jovens, em função das condições vivenciadas por eles, seus estilos de vida, gostos, territórios que transitam, se mostram mais evidentes. $\mathrm{O}$ jovem dentro da sociedade rompe barreiras em relação à faixa etária determinista utilizada por alguns autores e pelo próprio IBGE para definir juventude. Na atualidade o jovem se coloca como ser ativo na sociedade e de transformação. Para Groppo (2015, p.07),

E a transformação social figuraria a esta geração eterna de modo completamente diferente. Entretanto, sempre aparecem novos participantes da vida social, enquanto outros desaparecem. Como já dito, membros de dada geração participam de seção limitada do tempo histórico. Como se acrescenta agora, a transmissão da herança cultural e a transição de uma geração a outra é um processo contínuo: não é marcada por uma ruptura bem estabelecida no tempo.

Sendo assim, o jovem se constrói e reconstrói em seu tempo e o local em que está inserido, como atores de suas vontades, desejos e ações próprias em seu tempo. A seguir discute-se a relação da juventude com o trabalho mais especificamente.

A inserção profissional, conforme Vernières (1997, APUD, OLIVEIRA 2012, p. 126), “[...] é o processo pelo qual os indivíduos que jamais participaram da população ativa ingressam em uma posição estável no sistema de emprego". O conceito está ligado ao término dos estudos e à busca de um posto de trabalho relacionado com o curso realizado. Segundo Rocha-de-Oliveira e Piccinini (2012), com a expansão dos estudos na França sobre o tema, na década de 70, em especial no âmbito econômico, diferentes campos procuraram pesquisar e compreender a temática, como a sociologia, na representação de autores como Dubar (2005; 2012), Galland (2001) e Nicole-Dancourt (1990).

O conceito versado por Dubar (2005) de inserção profissional está como imerso no contexto sócio-histórico, tendo por base a vida dos jovens, suas experiências e a construção de sua identidade. Ante os estudos sociológicos e da pesquisa aqui apresentada, assume-se a ótica dos jovens como sujeitos histórico-socioculturais. Estes compreendem o mundo e realizam suas escolhas a partir da realidade e dos contextos que estão inseridos, o que contribui com a vertente sociológica da inserção profissional. 
Na vertente sociológica, a inserção profissional é ao mesmo tempo profissional e sociocultural, devendo ser relacionada aos demais elementos da sociedade. Essa perspectiva congrega a ideia que existem múltiplas juventudes vinculadas às dimensões temporais e culturais. Juventudes que são distintas em modos de pensar, de agir e de viver o processo de passagem [...] que, por consequência, vivem modos distintos de inserção profissional (ROCHA-DE-OLIVEIRA; PICCININI, 2012, p. 70).

Existem múltiplos mercados de trabalho que se adaptam e modificam de acordo com o movimento de segmentos de produção, profissão, regiões e do trabalhador (ROCHA-DE-OLIVEIRA, 2012). O processo de inserção profissional é característico para cada jovem a partir de sua formação inicial e do momento de ingresso no mundo do trabalho, “[...] integração profissional, social, cívica e simbólica; e, por último, falar de inclusão" (ALVEZ, 2018, p.89).

\section{OS TRILHOS DA PESQUISA: PROCEDIMENTOS METODOLÓGICOS}

A abordagem da pesquisa foi qualitativa, neste aspecto, as relações, dimensões construtivas e estabelecidas geraram mais sentidos para o desenvolvimento da investigação, permitindo reflexões mais profundas a partir das respostas dos sujeitos (MELUCCI, 2005), buscando compreender os indivíduos por meio de seus próprios termos (GOLDENBERG, 2015).

Os sujeitos participantes da pesquisa homens e mulheres, todos egressos de uma Universidade situada do Alto Vale do Itajaí, Santa Catarina, Brasil, e egressos dos cursos de Administração, Ciências Contábeis, Ciências Econômicas, Direito, Enfermagem, Educação Física Bacharelado, Educação Física Licenciatura, Engenharia Civil, Psicologia e Sistemas de Informações, concluintes no período de 2014 a 2018. A coleta de dados aconteceu via formulário, na plataforma do Google Drive, a qual o link foi encaminhado via e-mail, em que estava disponível o questionário semiestruturado, ao todo foram encaminhados 1.300 e-mails, 633 foram entregues e 134 respondidos.

De acordo com Gil (2008, p.121), este procedimento é composto "por um conjunto de questões que são submetidas às pessoas com o propósito de obter informações sobre conhecimentos, crenças, sentimentos valores e interesses [...]". Os resultados obtidos através do questionário complementam “[...] a informação que não pode ser diretamente 'visualizada' a partir de uma massa de dados, poderá sê-lo se tais dados 
sofrerem algum tipo de transformação que permita uma observação de outro ponto de vista (FALCÃO; RÉGNIER, 2000, p. 232)”, auxiliando a extração de dados que foram estabelecidos como objetivos dessa pesquisa.

Para a análise dos dados estatísticos e as demais informações qualitativas, a técnica utilizada foi “Análise de Conteúdo”, que, após o posicionamento metodológico e epistemológico, vai ao encontro do que Franco (2018, p.12) aborda, "o ponto de partida da Análise de Conteúdo é a mensagem, seja ela verbal (oral ou escrita), gestual, silenciosa, figurativa, documental ou diretamente provocada [...]. Relação que se dá na prática social e histórica da humanidade e que se generaliza via linguagem".

Além da definição de Franco (2018) acerca do conceito epistemológico e base da “Análise de Conteúdo”, buscaram-se também em Bardin (2016, p.36) outras explicações. Fica evidente que um método empírico que se dedica a todos os tipos de interpretação que se pretende a partir da "análise de conteúdo adequada ao domínio e ao objetivo pretendido tem de ser reinventado a cada momento [...]”. Ao escolher a Análise de Conteúdo, foi necessário o cuidado na forma de interpretação dos dados a partir dos sentidos atribuídos pelos sujeitos pesquisados.

\section{A TRAJETÓRIA EDUCACIONAL E INSERÇÃO PROFISSIONAL}

Cada ser humano traz consigo suas características que as tornam peculiares diante de outras. Apresentar os sujeitos desta pesquisa e expressar seus atributos sem os conhecer é entrar no íntimo daqueles que, de forma voluntária, se dispuseram a participar da investigação e expuseram suas considerações de maneira expressiva com relação à temática pesquisada. E manifestaram suas opiniões sobre educação, trabalho e aspectos de sua vida, ressaltadas por meio das 29 (vinte e nove) perguntas respondidas pelo Google Formulário.

Para caracterizar o perfil dos 134 (cento e trinta e quatro) jovens egressos que concluíram a graduação, no período de 2014 a 2018, foram analisadas respostas sobre características pessoais, conceitos e opiniões relativas aos sentidos da educação e do trabalho, inserção profissional e as perspectivas durante e após a formação acadêmica.

Para preservar a identidade dos participantes, identificamos com as iniciais do curso que foram graduados, ADM, PSI, BSI, etc., quando necessário, foi acrescentado um número para distinguir uma narrativa da outra, sendo ambos do mesmo curso. Para 
melhor percepção das áreas de formação, a Tabela 1 destaca os egressos categorizados por cursos e ano de conclusão.

Tabela 1 Distribuição dos egressos por área de formação

\begin{tabular}{l|c|c|c|c|c|c}
\hline \multicolumn{1}{c|}{ CURSO } & $\mathbf{2 0 1 8}$ & $\mathbf{2 0 1 7}$ & $\mathbf{2 0 1 6}$ & $\mathbf{2 0 1 5}$ & $\mathbf{2 0 1 4}$ & TOTAL \\
\hline Administração & 8 & 10 & 11 & 11 & 6 & 46 \\
\hline Ciências Contábeis & 2 & 3 & 1 & 3 & 0 & 9 \\
\hline Ciências Econômicas & 0 & 1 & 3 & 1 & 1 & 6 \\
\hline Direito & 4 & 5 & 7 & 5 & 1 & 22 \\
\hline Ed. Física Bacharelado & 0 & 3 & 5 & 2 & 1 & 11 \\
\hline Ed. Física Licenciatura & 0 & 1 & 1 & 2 & 2 & 6 \\
\hline Enfermagem & 0 & 0 & 0 & 1 & 1 & 2 \\
\hline Engenharia Civil & 0 & 3 & 1 & 5 & 3 & 12 \\
\hline Psicologia & 4 & 3 & 3 & 1 & 1 & 12 \\
\hline Sistemas de Informação & 0 & 4 & 0 & 3 & 1 & 8 \\
\hline Total & 18 & 33 & 32 & 34 & 17 & 134 \\
\hline
\end{tabular}

Fonte: elaborado pelas pesquisadoras com base nos dados obtidos na coleta de dados (2020).

O maior número de respondentes do questionário agrupou-se no curso de Administração, seguido do curso de Direito. Acredita-se que esta representatividade ocorreu pela demanda de oferta dos cursos, ambos ofertados nos campi da instituição. Em contrapartida, o número menor de respostas (02) foi do curso de Enfermagem, ofertado apenas no campus central, não justificando a baixa oferta de respostas, deste modo, considerou-se o não recebimento de e-mail.

No que diz respeito ao ano de conclusão do curso de graduação, os egressos foram distribuídos em um número considerável para cada período, trazendo contributos importantes para a pesquisa no que se refere à inserção profissional no mercado de trabalho (durante e após a graduação), podendo assim expressar experiências diversas no processo de educação e trabalho.

Estes que participam da pesquisa residem em regiões diversas de nosso Estado de Santa Catarina, Brasil e em outros países, como demonstraram os dados obtidos através do questionário. Na região do Alto Vale do Itajaí, encontrou-se a maior concentração dos residentes egressos, $95 \%$ trabalham nas cidades que compõem a região, seguido do Litoral Catarinense, em um total de 3\%, e a região do Planalto Serrano, com representatividade de 1\%. Uma das egressas migrou para Dublin, na Irlanda em busca de novas oportunidades de trabalho, "em tempos de ampliação do desemprego, da precarização do trabalho e de uma situação de permanente angústia e insegurança 
daqueles que, para sobreviver, tem apenas sua força de trabalho para vender" (FRIGOTTO, 2001, p. 72).

Para os jovens egressos, a busca por um trabalho traz sentimentos que são alimentados durante a sua trajetória acadêmica e, por vezes, os acompanham em seu percurso formativo, podendo ser compartilhado ou trilhado sozinho. Nesta trajetória, $48 \%$ dos entrevistados estão residindo com o cônjuge, $46 \%$ com os pais, $04 \%$ sozinhos e $2 \%$ outros tipos de moradia. Embora se apresente um percentual de moradia com cônjuges maior, $52 \%$ identificam-se como solteiros e $22 \%$ casados, $25 \%$ estão em união estável e $1 \%$ viúvo (a). Tais porcentagens ficaram evidentes no gráfico abaixo, que retrata a idade dos participantes da pesquisa em blocos.

Gráfico 1 Idade dos participantes da pesquisa

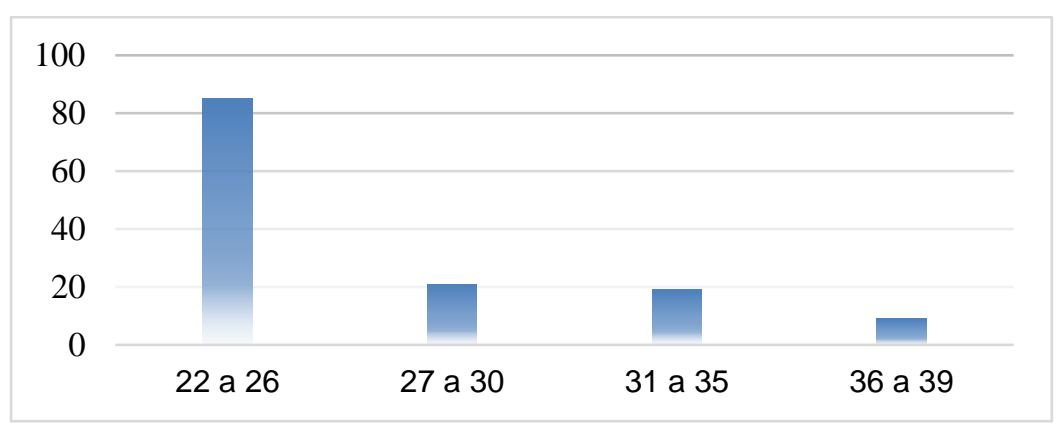

Fonte: elaborado pelas pesquisadoras com base nos dados obtidos na coleta de dados (2020).

Os jovens egressos se encontravam no momento da pesquisa na faixa etária dos 22 aos 39 anos, com destaque para o bloco com maior representatividade de idade de 22 a 26 anos, 85 egressos. Como pode ser observado no gráfico, é o número maior de estudantes que agora são egressos, faixa etária superior, como é definido pelo Instituto Brasileiro de Geografia e Estatística - IBGE, o termo juventudes/jovens, isto ocorre em função do período de conclusão da graduação (2014 a 2018) e do envio do questionário (2019/2020). Essa questão nos levou à reflexão sobre o ingresso no ensino superior tardio em que marca uma nova etapa geracional não comum, alinhando à formação acadêmica que se integra a um espaço de predominância jovem, uma cultura juvenil, com traços comuns e diferenciados ao mesmo tempo (PAIS, 2003).

É importantíssimo assinalar que essa explicação, no caso de definição do que seja juventude ou juventude(s), perpassa por aspectos "historicizados" com tratamento muitas vezes relacional, uma vez que, segundo Sposito (1999, p 98), “ser ou não ser considerado jovem depende de circunstâncias históricas determinadas, como é o caso, por exemplo, 
de algumas estatísticas de países europeus na atualidade, que consideram jovens os indivíduos que possuem até 29 anos". E atualmente, se formos considerar a expectativa de vida, essa faixa etária segue até 34 ou 39 anos (RAITZ, 2003).

Tais características são verificadas nas sociedades avançadas em que há um prolongamento da escolaridade, fato este que ocasiona um período maior de convivência com o grupo familiar de origem, de acordo com Raitz (2003). Esse alongamento ou alargamento dos limites superiores da faixa etária é verificado naquilo que marca a vida adulta, inserção no mercado de trabalho, designado de vida ativa conforme Raitz (2003). Porém, diz a autora, o contexto do desemprego estrutural nas sociedades contemporâneas dificulta ou mesmo não assegura a inserção profissional do jovem no mercado de trabalho, mesmo após um período de preparação de sua escolaridade.

Neste sentido, Sposito (2000) explica que, para grande parcela dos setores populares, a inserção imediata no mundo do trabalho torna-se, em grande medida, o horizonte imediato. Assim, esta definição possibilita, em alguns casos, a incorporação de pesquisas de faixas etárias um pouco anteriores ou superiores ao universo de 15-24 anos. A definição da faixa etária nesta investigação foi baseada nos estudos sobre juventude, como já mencionado, em alguns casos retoma-se a discussão acerca da flexibilidade de faixas inferiores e superiores. O que é expressivo ressaltar, no que tange aos jovens, é que as escolhas sempre são redefinidas,

\footnotetext{
Neste caso, estabelecer fronteiras para nós mesmos, e no caso dos jovens, num mundo de incertezas, as escolhas são redefinidas constantemente, mas sem deixar de levar em consideração algo já construído anteriormente, mudando a forma, permanecendo o mesmo. Nesta perspectiva, a identidade juvenil passa a ser compreendida como um processo de contínua transformação, tanto individual como coletiva, que perpassa pela teia de suas múltiplas experiências e não mais determinada por sua idade biológica (RAITZ, 2003, p.43).
}

A totalidade do trabalho a partir das novas características descritas por Antunes e Alves (2004), da venda da força de trabalho por um salário, apressa a classe que vive do trabalho na busca incessante por um emprego. Em especial tal fato se observa no caso deste segmento dos jovens aqui pesquisados, que, após a conclusão do curso ou mesmo antes, buscavam sua inserção profissional. Para 109 (cento e nove) egressos, o ingresso no mercado de trabalho, em sua área de formação, ocorreu em menos de 1 (um) ano após sua formatura, já para 15 (quinze) egressos, este período ficou entre 02 e 03 anos, e para 10 (dez) egressos, o caminho de inserção em sua área durou mais de 03 anos. A Tabela 
02 abaixo demonstra o período para inserção profissional e a área de formação dos egressos, após a conclusão do curso de graduação.

Tabela 2 - Período de inserção por área de formação após conclusão da graduação

\begin{tabular}{|c|c|c|c|}
\hline Cursos & Menos de 1 ano & De 02 a 03 anos & Mais de 03 anos \\
\hline Administração & 41 & 04 & 01 \\
\hline Ciências Contábeis & 08 & - & 01 \\
\hline Direito & 21 & 01 & - \\
\hline Economia & 05 & & 01 \\
\hline Educação Física Bacharelado & 10 & 01 & - \\
\hline Educação Física Licenciatura & 02 & 02 & 02 \\
\hline Enfermagem & 01 & 01 & - \\
\hline Engenharia Civil & 07 & 03 & 02 \\
\hline Psicologia & 07 & 03 & 02 \\
\hline Sistemas de Informação & 07 & - & 01 \\
\hline Total & 109 & 15 & 10 \\
\hline
\end{tabular}

Fonte: elaborado pela pesquisadora com base nos dados obtidos na coleta de dados (2020).

Esta transição universidade/mercado de trabalho é apresentada por Rocha-DeOliveira e Piccinini (2012), não apenas como um mecanismo econômico, como descrito por Antunes e Alves (2004), mas como "resultante de interações diversas e complexas que se situam geralmente em dois níveis: institucional e individual" (ROCHA-DEOLIVEIRA e PICCININI, 2012, p.48), as experiências construídas a partir de seus valores e formação.

O processo de inserção profissional para a maioria dos egressos ocorreu de forma rápida em seu campo de formação. A região na qual está localizada a instituição é formada por empresas de diversas áreas - metal mecânico; vestuário; alimentício; transporte; informática, e se destaca na produção agrícola; - entre tantas outras áreas abrangentes que ofertam emprego nas áreas citadas. O período de conclusão dos cursos até o período de participação na pesquisa foi de 6 (seis) a 2 (dois) anos, o que pode ocasionar mudanças na área de atuação, desemprego, entre tantos outros fatores.

Conforme a Tabela 2 exposta anteriormente, os 134 (cento e trinta e quatro) egressos responderam que conseguiram trabalho em sua área de formação entre 01 ano e mais de 03 anos. Com as modificações que ocorreram no mundo de trabalho nos últimos anos, apenas 91 (noventa e um) jovens egressos permaneciam atuando diretamente em sua área de formação acadêmica.

Destes, 36 (trinta e seis) estão ativos no mercado e 07 (sete) alegaram que estão atuando em um emprego que não condiz com sua formação acadêmica, justificando suas respostas por estarem em áreas que ofereçam uma estabilidade financeira melhor do que 
seria trabalhar na sua área de formação, em áreas de saúde e beleza, corretor de seguros, leiloeiros e funcionários públicos ou complementam a renda exercendo sua profissão em turno contrário ao de seu outro trabalho, como exemplo, os psicólogos.

A estrutura do mercado de trabalho também tem passado por mudanças [...] A educação e a formação profissional aparecem hoje como questões centrais, pois elas são conferidas funções essencialmente instrumentais, ou seja, capazes de possibilitar a competividade e intensificar a concorrência, adaptar trabalhadores às mudanças técnicas e minimizar os efeitos do desemprego (SEGNINI, 2000. p. 73).

Os jovens egressos trabalhadores (as) atuam em empresas públicas e privadas e expressam os motivos pelos quais não exercem atividade profissional em sua área de formação.

Quadro 1 - Motivo por não exercer atividade na área de formação

\begin{tabular}{|l|c|c|}
\hline \multicolumn{1}{|c|}{ Curso } & Total & Percentual \\
\hline Exerço Atividade na Área & 86 & $64 \%$ \\
\hline Melhor oportunidade em outras áreas & 14 & $11 \%$ \\
\hline Motivos particulares & 18 & $13 \%$ \\
\hline Não me identifiquei com a profissão & 4 & $3 \%$ \\
\hline Mercado de trabalho saturado & 12 & $9 \%$ \\
\hline Total & 134 & $100 \%$ \\
\hline
\end{tabular}

Fonte: elaborado pela pesquisadora com base nos dados obtidos na coleta de dados (2020).

Ao aprofundar os motivos pelos quais os egressos não estão atuando em sua área de formação visíveis no Quadro 6, números que divergem da Figura 10, algumas inconsistências aparecem. No que está de acordo com a primeira resposta "Exerço atividade na área", 64\% confirmam estarem de fato trabalhando em sua área de formação. Já, na figura anterior, em números brutos, 91 confirmaram exercer atividade profissional na área de formação "Sim, na minha área de formação acadêmica", o que diverge em 05 repostas.

Ao retomar o questionário e as codificações "o processo pelo qual os dados brutos são transformados sistematicamente e agregados em unidades, as quais permitem uma descrição exata das características pertinentes ao conteúdo" (BARDIN, 2016, p. 133), não foram identificadas divergências numéricas, o que pode ter modificado a resposta anterior é o maior número de opções ou a identificação de uma característica próxima com sua realidade. Ao expressarem ter encontrado novas oportunidades em outras áreas, motivos particulares, não identificação com a profissão e o mercado de trabalho saturado, concordamos com Melucci (1997, p.07), quando menciona nesta passagem; 
Em uma sociedade que está quase que inteiramente construída por nossos investimentos culturais e simbólicos, tempo é uma das categorias básicas através da qual nós construímos nossa experiência, o tempo se torna uma questão-chave nos conflitos sociais e na mudança social. A juventude que se situa, biológica e culturalmente, em uma íntima relação com o tempo, representa um ator crucial [...] (MELUCCI, 1997, p.07).

A relação do tempo com as experiências desenvolvidas impacta no processo formativo desses jovens, pois ocorrem mudanças rápidas para inserção e permanência no mercado de trabalho. Para melhor compreensão das respostas, o Quadro 2 revela tais informações por área de formação e opções de respostas.

Quadro 2- Atividade de trabalho por curso

\begin{tabular}{|c|c|c|c|c|c|c|}
\hline Cursos & $\begin{array}{c}\text { Quantidade } \\
\text { de } \\
\text { respostas }\end{array}$ & $\begin{array}{c}\text { Exerço } \\
\text { atividade } \\
\text { na área }\end{array}$ & $\begin{array}{c}\text { Melhor } \\
\text { oportunidade } \\
\text { em outras } \\
\text { áreas }\end{array}$ & $\begin{array}{c}\text { Motivos } \\
\text { particulares }\end{array}$ & $\begin{array}{c}\text { Não me } \\
\text { identifiquei } \\
\text { com a } \\
\text { arofissão }\end{array}$ & $\begin{array}{c}\text { Mercado } \\
\text { de } \\
\text { trabalho } \\
\text { saturado }\end{array}$ \\
\hline Administração & 46 & 31 & 05 & 08 & - & 02 \\
\hline Ciências Contábeis & 09 & 05 & 3 & 01 & - & - \\
\hline Direito & 22 & 16 & 1 & 04 & - & 01 \\
\hline Economia & 06 & 01 & 1 & 01 & 03 & - \\
\hline $\begin{array}{c}\text { Educação Física } \\
\text { Bacharelado }\end{array}$ & 11 & 09 & 1 & - & 01 & - \\
\hline $\begin{array}{c}\text { Educação Física } \\
\text { Licenciatura }\end{array}$ & 06 & 03 & - & 02 & - & 1 \\
\hline Enfermagem & 02 & 02 & - & - & - & - \\
\hline Engenharia Civil & 12 & 08 & - & - & - & 4 \\
\hline Psicologia & 12 & 05 & 2 & 1 & - & 4 \\
\hline $\begin{array}{c}\text { Sistemas de } \\
\text { Informação }\end{array}$ & 8 & 06 & 1 & 1 & - & 0 \\
\hline Total & $\mathbf{1 3 4}$ & $\mathbf{8 6}$ & $\mathbf{1 4}$ & $\mathbf{1 8}$ & $\mathbf{4}$ & $\mathbf{1 2}$ \\
\hline
\end{tabular}

Fonte: elaborado pela pesquisadora com base nos dados obtidos na coleta de dados (2020).

$\mathrm{Na}$ análise dessas informações que dão visibilidade à busca no processo de educação e trabalho, podemos dizer que é durante esse procedimento que criamos consciência de nós mesmos, na trajetória como indivíduos que percebemos as contradições que surgem em nossa sociedade, bem como no processo por busca de trabalho (SEGNINI, 2000).

Os jovens vivem o presente, são mais imediatistas e ansiosos, inclusive na busca por trabalho. Neste aspecto, Melucci (1997, p.08) menciona que "a juventude, por causa de suas condições culturais e biológicas, é o grupo social mais diretamente exposto a estes dilemas, o grupo que os torna visíveis para a sociedade como um todo", os dilemas de nossa sociedade contemporânea em diferentes esferas sociais. 
O período de graduação é um momento de busca e aperfeiçoamento para o ingresso ao mercado de trabalho, ante os impactos que esses jovens egressos sofreram ao longo da graduação e o sentimento frente à busca por inserção profissional, foi questionado como estavam se sentindo quanto à qualificação profissional, se estavam preparados(as) para a atuação no mercado de trabalho. Conforme a análise das respostas, 64 (sessenta e quatro) acreditavam estar aptos para atuar no mercado de trabalho, como descreve o acadêmico, que diz ocorrer isso por já exercer uma função em um local de atuação profissional. "Sim, preparado! pois já atuava há 03 anos como estagiário em academia, caso contrário, não sei se estaria" (EDF1).

Outros egressos mencionaram que estavam aptos por já estarem atuando direta e indiretamente no mercado de trabalho, o relato de um egresso de Engenharia Civil é expressivo: "Como consegui uma inserção no mercado de trabalho a partir da $5^{\circ}$ fase do curso, me senti preparado para atuar [...]" (EGC1). A inserção profissional durante a graduação, sem sombra de dúvidas, oportuniza experiências significativas e experiências que auxiliam no ingresso ao mundo do trabalho.

O número de respostas dos egressos que dizem não se sentirem preparados (as) para atuar no mercado de trabalho foi de 50 (cinquenta), um número bastante significativo. Os motivos relatados são: falta de disciplinas práticas que condizem com a realidade de empresas, escritórios, consultórios, academias, etc. Um dos egressos conta que foi necessária a busca de um profissional mais experiente para auxiliar em sua preparação, "não estava preparada, precisei buscar ajuda de profissionais mais experientes quando entrei no mercado de trabalho" (EGC2).

A continuidade nos estudos auxiliou outra egressa em seu processo de qualificação profissional: "Não me sentia preparada e não possuía muito network. Consegui atuar no ramo desejado apenas 3 (três) anos após a conclusão do curso de graduação, já concluindo minha especialização" (ADM3). Os que conseguiram a ajuda de outros profissionais e a continuidade dos estudos se tornaram mais qualificados e preparados. Infelizmente esta não é uma realidade geral, o que leva estudantes a abandonarem totalmente sua área de formação, "não estava preparado, seja por isso, não segui a profissão de contador" (CCO1).

A insegurança para atuar no mercado de trabalho aparece nas respostas de 20 (vinte) egressos, descrevendo medos, dúvidas e outros sentimentos que acabam gerando incertezas no momento da busca por emprego ou para se inserir no trabalho: "Estava 
insegura, muitas incertezas sobre a vida profissional (EFM01); me formei carregada de incertezas do que o futuro reservava e a aceitação profissional" (DIR3). As mudanças que acontecem no mundo do trabalho trazem angústias a partir do conhecimento adquirido durante o período da graduação, "o mercado de tecnologia e inovação é muito veloz, tudo o que aprendi na graduação, no inicio do curso, já estava desatualizado, isso gerou angústias e medo" (BSI1).

A transição universidade-mercado de trabalho é um eixo central na vida do jovem na construção de sua vida adulta e de seu projeto profissional. Os sentimentos expressos pelos egressos resultam, às vezes, em perdas, o contexto complexo em ser aluno (a) e a necessidade de construir uma identidade própria ao assumir os desafios propostos após sua formação (MELO; BORGES, 2007). Enfrentar um mercado competitivo e que por vezes o curso tão sonhado pode se tornar um impeditivo de inserção profissional.

\section{CONSIDERAÇÕES FINAIS}

A trajetória de formação e inserção profissional se constituiu na percepção dos participantes da pesquisa como um momento de insegurança, cheio de dúvidas e anseios, ao mesmo tempo, se configurou como uma forma de autonomia, tomada de decisões e o momento de demonstrar sua aptidão profissional como graduado, estando apto a inserirse no mercado de trabalho. Para outros jovens este é um momento em que se percebe que a graduação tão almejada e sonhada, dificulta sua inserção no mercado de trabalho, por ser um campo concorrido ou até mesmo com saturação de profissionais na área, o que os faz com que permaneçam atuando em uma área diversa a de sua formação.

No que diz respeito à relação educação e trabalho, os jovens egressos ressaltaram que o curso de graduação resultou em impactos positivos e essenciais para a atuação no mercado de trabalho, como também para a sua vida pessoal, valorizando a formação que receberam, assim como evidenciaram a continuidade dos estudos como essencial para estarem ativos no mercado e abertos às novas oportunidades.

Visando identificar as influências e dificuldades de inserção profissional, os resultados apontaram que os motivos para a escolha do curso estão relacionados ao mercado de trabalho, influência, oportunidades, sonhos e à universidade. Eles relataram que, ao sofrer a influência para a decisão de escolha do curso de graduação por parte da família, o que sobressaiu foram as questões financeiras. Por outro lado, alguns jovens 
egressos já estavam determinados a realizar a graduação dos sonhos, nem que para isto fosse necessário esperar.

Quanto à inserção profissional, resulta num momento importante para se estabelecer ou se manter na profissão, ocupar um espaço no mercado de trabalho. Sobre as dificuldades de inserção profissional, verificou-se que a falta de oportunidades, mercado saturado, salário, concorrência, reconhecimento, falta de experiência e insegurança foram os motivos principais.

A educação, para os referidos jovens, consiste num momento de oportunidade para seu crescimento profissional e pessoal. Os sentidos da educação atribuídos por eles passam por mudanças, amadurecimento, transformações, realização, sonho, conhecimento e empoderamento. Neste aspecto, a educação representa a mudança e a preparação para a entrada no mundo laboral.

\section{REFERÊNCIAS}

ABRAMO, H. W. Entrevista concedida ao projeto Especial Juventude que aborda questões de educação, violência e descriminação. 2018. Disponível em: https://educacaoeparticipacao.org.br/especialjuventude/index.html\#inicio Acesso em 30 de junho de 2019.

ALVES, Natália. Juventudes e Inserção Profissional. Biblioteca Nacional de Portugal, 2018.

ANTUNES, Ricardo. O Privilegio da Servidão: o novo proletariado de serviços na era digital. São Paulo: Boitempo, 2018.

ANTUNES, Ricardo. O caráter polissêmico e multifacetado do mundo do trabalho. Trabalho, Educação e Saúde. 1(2): 229-237, 2003.

BARDIN, Laurence. Análise de Conteúdo. São Paulo: Edições 70, 2016.

DAYRELl, J. O jovem como sujeito social. Revista Brasileira de Educação, Campinas, SP, n. 24, p. 40-52, 2003.

DUBAR, Claude. A socialização: construção das identidades sociais e profissionais. São Paulo: Martins Fontes, 2005.

DUBAR, Claude. A construção de si pela atividade de trabalho: a socialização profissional. Cadernos de Pesquisa. Trad. Fernando Machado. V. 42. N.146 p. 351-357 Maio/ago. 2012. 
FALCÃO, J. T. da R.; RÉGNIER, J. Sobre os métodos quantitativos na pesquisa em ciências humanas: riscos e benefícios para o pesquisador. Revista Brasileira de Estudos Pedagógicos, Brasília, v. 81, n. 198, p. 229-243, maio. /ago. 2000.

FRANCO, Maria Laura Puglisi Barbosa. Análise de Conteúdo. 5.ed. Campinas: editora Autores Associados, 2018.

FRIGOTTO, Gaudêncio. Educação e Trabalho: bases para debater a Educação Profissional Emancipadora. Perspectiva, Florianópolis, v.19, n.1, p. 71-87, jan/jun. 2001.

GALLAND, Olivier. Adolescence, post-adolescence, jeunesse : retour sur quelques interprétations, Revue Française de Sociologie, 42, 4, p. 611-640. 2001.

GIL, Antonio Carlos. Métodos e técnicas de pesquisa social. 6.ed. São Paulo: Atlas, 2008.

GOLDENBERG, Mirian. A arte de pesquisar: como fazer pesquisa qualitativa em Ciências Sociais. Rio de Janeiro: Record, 2015.

GROPPO, L. A. Teorias crítica da juventude: geração, moratória social e subcultura juvenis. Revista Em Tese, Florianópollis, v. 12, n.1, jan./jul., 2015.

MELO, S. L. de; BORGES, L. de O. A Transição da Universidade ao Mercado de Trabalho na Ótica do Jovem. Psicologia Ciência e Profissão, v. 27 (3). 376 - 395, 2007.

MELUCCI, Alberto. Juventude, tempo e movimentos sociais. Revista Brasileira de Educação. No5 Mai/Jun/Jul/Ago 1997; Set/Out/nove/dez No6, 1997 p. 05-14. Originalmente publicado em: Revista Young. Estocolmo: v.4, n², 1996, p.3-14; traduzido por: Angelina Teixeira Peralva.

MELUCCI, Alberto. Por uma sociologia reflexiva: pesquisa qualitativa e cultura. Trad. Maria do Carmo Alves do Bomfim. Petrópolis, RJ: Vozes, 2005.

NICOLE-DRACOURT, C. Le labyrinthe de l'insertion. Paris. La documentation française, 1990.

OLIVEIRA, S.R. de. Inserção profissional: perspectivas teóricas e agenda de pesquisa. Rio de Janeiro. Revista Pensamento Contemporâneo na Administração. V. 6. n.1. Jan/mar, 124-135. 2012.

PAIS, José Machado. Culturas Juvenis. Porto: Impressa Nacional Casa da Moeda, Lisboa, Ed. 2º 2003.

RAITZ, Tânia Regina. Jovens, trabalho e educação: rede de significados dos processos identitários na Ilha de Santa Catarina. Orientador: Nilton Bueno Fischer. Tese (Doutorado em Educação). Universidade Federal do Rio Grande do Sul - UGRGS, Porto Alegre, 2003. 
RAITZ, Tânia Regina. Jovens, Trabalho e Educação: Processos identitários na contemporaneidade. Revista Reflexão e Ação, Santa Cruz do Sul, v. 19, n1, p.78-94, jan./jun. 2011.

ROCHA-DE-OLIVEIRA, Sidnei; PICCININI, Valmiria Carolina. Uma análise sobre a inserção profissional de estudantes de administração no Brasil. Rev, Ver. ADM. Mackenzi, v.13, n.2. São Paulo, Sp, Mar/abr. p. 44-75. 2012.

SEGNINI, Leticia Rolfsen Petrilli. Educação e Trabalho: uma relação tão necessária quanto insuficiente. Rev. São Paulo Perspectiva. vol.14, n.2, pp.72-81, 2000.

SPOSITO, Marília Pontes. Juventude: Crise, identidade e escola DAYRELL, Juarez (Org). Múltiplos olhares sobre educação e cultura. Belo Horizonte: UFMG, 1999.

SPOSITO, Marília Pontes. Algumas hipóteses sobre as relações entre movimentos sociais, juventude e educação. Revista Brasileira de Educação. São Paulo: ANPED, n. 13, 2000.

\section{Recebido em: 20/11/2021}

Aprovado em: 23/12/2021

Publicado em: 27/12/2021 